\title{
Electrorectogram study of the neuropathic rectum
}

\author{
A Shafik \\ Professor and Chairman, Department of Surgery and Research, Faculty of Medicine, Cairo University, Cairo, \\ Egypt
}

The rectal electrical activity was studied by electrorectogram (ERG) in 28 patients with spinal cord injury (SCI) (mean age 46.6 years, 18 men and 10 women) and nine healthy volunteers (controls). Nineteen patients had an upper motor neuron lesion (UMNL) and 9 a lower motor neuron lesion (LMNL). The ERG was recorded by a monopolar silversilver chloride electrode applied to the rectal mucosa by suction. Simultaneous recording of the rectal and rectal neck pressures was performed. At least four recording sessions of $120 \mathrm{~min}$ each were done for every subject. No complications were encountered during the test. The ERG in normal subjects showed pacesetter potentials (PP) with a regular rhythm and constant frequency and were reproducible in the individual subject. PP were followed by action potentials (AP) which had an inconsistent frequency and were associated with increased rectal pressure. The ERG in UMNL patients exhibited 'dysrhythmia' with irregular frequency, amplitude and velocity. The AP did not show in any recording. LMNL patients had a 'silent' ERG. In conclusion, two patterns of ERG could be identified in SCI patients: dysrhythmic and silent. The cause of the disordered ERG could be due to derangement of the intrinsic rectal conducting system.

Keywords: rectum; rectal electric activity; electrorectography; rectal motility; manometry; electrophysiology of smooth muscle; action potentials

\section{Introduction}

Rectal dysfunction is a frequent finding in neurological diseases. ${ }^{1}$ The rectal detrusor behaviour differs according to the type of neurological affection. In SCI, the level of the lesion is decisive for the type of rectal dysfunction. ${ }^{2,3}$ In patients with upper motor neuron lesions, the rectum becomes hyperreflexic, and defecation is reflex and commonly initiated by somatic stimuli. In patients with lower motor neuron lesions, the rectum is areflexic, and defecation is induced by enemas. ${ }^{3-5}$

The defecation mechanism is intricate. It comprises rectal detrusor contraction and rectal neck (anal canal) opening. ${ }^{6,7}$ Many voluntary and reflex actions are involved. ${ }^{8-12}$ Recent studies have shown that the rectal muscle coat possesses electrical activity which appears to control rectal motility. ${ }^{13-16}$ The electric activity is manifested by regular slow waves or pacesetter potentials (PP). The PP frequency is species dependent with a mean of $4.8 \pm 0.6 \mathrm{~s}$.d. cycle $\mathrm{min}^{-1}$ in dogs and $2.6 \pm 0.4$ s.d. cycle $\min ^{-1}$ in humans. It was constant on all of the test days with only occasional variations. PP were followed by action potentials (AP) which had inconsistent frequency and were accompanied with increased rectal pressure denoting rectal contractions. The studies suggested that PP start at the rectosigmoid

Correspondence: A Shafik, 2, Talaat Harb Street, Cairo, Egypt junction and propagate caudally along the rectum. ${ }^{13,14}$ Previous investigations had suggested that the rectosigmoid junction is the site of a pacemaker which seems to trigger the PP. ${ }^{17,18}$ The PP are believed to initiate AP and to pace the rectal contractile activity in terms of direction and frequency..$^{13,14}$

Since rectal motility is proposed to be controlled by PP, disordered rectal electric rhythm and rate which we call 'dysrhythmia' may cause rectal dysmotility or defecation disorders. The present communication studies the rectal electric activity by electrorectograms (ERG) in patients with SCI aiming at characterizing an ERG pattern for such disorders which may be used as an investigative tool for their diagnosis.

\section{Subjects}

Twenty eight patients with SCI entered the study after signing an informed consent. The duration of injury varied from 6 to 11 years (mean $9.2 \pm 3.6$ s.d. years). Ages varied from 28 to 64 years (mean $46.6 \pm 11.5$ s.d. years). Eighteen were men and 10 women. Nineteen of the patients had a complete SCI above the level of the conus medullaris; 12 were men and seven women. Neurological examination showed skeletal muscle spasticity distal to the lesion, hyperreflexia of deep tendon reflexes and extensor plantar responses. Defecation was reflex and was elicited by somatic stimuli such as massaging the rectal neck and tapping the lower 
part of the abdomen. The EMG of the external anal sphincter showed increased activity.

Nine of the patients had lower motor lesions. Six were men and three women. There was laxity of anal sphincters, flaccid paralysis of the lower extremities and depressed or absent deep tendon reflexes. Defecation was accomplished by enemas. The EMG activity of the external anal sphincter was diminished or absent.

Nine healthy volunteers were included in the study as controls. They matched the study group in age and gender. Ages ranged from 32 to 62 years (mean $44.8 \pm 10.9$ s.d. years), six were men and three women. They had no anorectal complaint at the time of presentation or in the past. Physical examination, including a neurological study, was normal. Informed consent was given before entering the study.

\section{Methods}

There was no special bowel preparation. All of the patients were instructed to evacuate their bowels by defecation or by normal saline enemas the night before the examination. Twenty four patients could defecate, and four could not and they used normal saline enemas. All of the patients were then subjected to saline enemas $2-3 \mathrm{~h}$ before testing so that any rectal irritation that may have resulted from the enemas would have subsided. The mucus on the rectal mucosa was removed by a swab soaked in sodium bicarbonate. The rectal electric activity was recorded by a $6 \mathrm{~F}$ catheter attached to the rectal mucosa by suction to a negative pressure which ranged from 50 to $100 \mathrm{~mm} \mathrm{Hg}$ and was maintained during the test.

Monopolar recordings were made from a silversilver chloride electrode $(0.2 \mathrm{~mm}$ diameter $)$ situated $1 \mathrm{~cm}$ from the tip of the catheter. The catheter tip was applied to the rectal mucosa, through a rectal speculum, at a distance of $8-10 \mathrm{~cm}$ from the anal orifice. Signals from the electrode were fed into an a.c. amplifier with a frequency response within $\pm 3 \mathrm{~dB}$ from $0.016 \mathrm{~Hz}$ to $1 \mathrm{kHz}$, and were displayed on an U-V recorder (SensorMedics, Anaheim, CA, USA) at a sensitivity of $1 \mathrm{mV} \mathrm{cm}^{-1}$. The indifferent electrode was a metal disc applied to the abdominal skin. The velocity of conduction was calculated by measuring the time required for conduction of the PP between two electrodes at a paper speed of $1 \mathrm{~cm} \mathrm{~s}^{-1}$.

Simultaneous recording of the rectal mechanical activity was achieved by measuring the rectal pressure by means of another $6 \mathrm{~F}$ catheter with two lateral $2 \mathrm{~mm}$ side ports and a closed distal end. The catheter was also placed in the rectum $8-10 \mathrm{~cm}$ from the anal orifice, and was infused with $37^{\circ} \mathrm{C}$ sterile saline at a rate of $2 \mathrm{ml} \mathrm{min}^{-1}$. It was connected to a strain gauge pressure transducer (Statham 230 B, Oxnard, California). A third $6 \mathrm{~F}$ catheter, balloon-tipped, was introduced into the rectal neck (anal canal) $)^{19,20} 2-3 \mathrm{~cm}$ from the anal orifice, and was connected to a Statham pressure transducer.

A $30 \mathrm{~min}$ allowance was given for adaptation to the electrode and manometric catheters. With the subject in the left lateral position, a 120 -min recording session was performed with each subject for at least four sessions, each on a different day.

'Rectal dysrhythmia' is differentiated as either bradyrectia, tachyrectia, or rectoarrhythmia. The normal rectal electric rhythm ranges from 2 to 4 cycles per minute $(\mathrm{cpm})$ (mean $2.6 \pm 0.4 \mathrm{cpm}) .{ }^{14}$ 'Bradyrectia' is defined as decreased PP frequency to less than $1 \mathrm{cpm}$, 'tachyrectia' as increased regular frequency to more than $6 \mathrm{cpm}$, and 'rectoarrhythmia' as an increased PP rhythm with irregular periods. The data were analysed statistically using Student's $t$ test.

\section{Results}

No complications were encountered from applying the electrodes to the rectum; the electrodes were well tolerated by the subjects during the test. They were kept attached to the rectal wall by maintaining the suction pressure constant throughout the test. All the subjects were evaluable. The results are presented with regard to (1) normal volunteers, (2) spastic paralysis patients, and (3) flaccid paralysis patients.

\section{Electrorectogram in normal subjects}

Table 1 depicts the frequency, amplitude and velocity of conduction of the PP. These variables were reproducible in the individual subject for each repetition of the test. The PP wave was triphasic with a small positive, a large negative and another small positive deflection (Figure 1). It had a regular rhythm and constant frequency in each individual on every test day.

The PP were followed by bursts of action potentials (AP) represented by negative deflection (Figure 1). The AP were inconsistent and occurred randomly, and their number varied from one time to the other during the test.

The manometric study recorded rectal pressure increase simultaneously with AP waves (Figure 2).

Table 1 The frequency, amplitude and velocity of pacesetter potentials recorded from the rectum of nine healthy volunteers $^{\mathrm{a}}$

\begin{tabular}{lccc}
\hline & $\begin{array}{c}\text { Frequency } \\
(\mathrm{cpm})\end{array}$ & $\begin{array}{c}\text { Amplitude } \\
(\mathrm{m} \mathrm{V})\end{array}$ & $\begin{array}{c}\text { Velocity } \\
\left(\mathrm{cms}^{-1}\right)\end{array}$ \\
\hline Range & $2-5$ & $1.7-3.8$ & $3.5-7.0$ \\
Mean & $3.1 \pm 0.9$ & $2.4 \pm 0.8$ & $5.2 \pm 1.2$ \\
\hline
\end{tabular}

a Values are given as mean \pm standard deviation $\mathrm{cpm}=$ cycle per minute
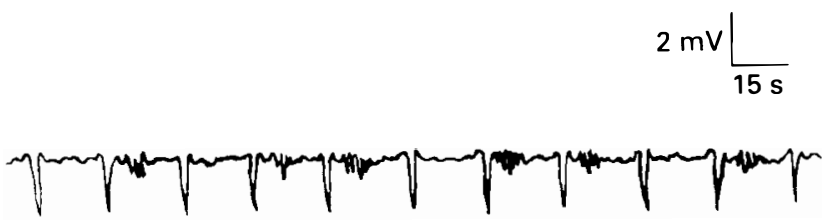

Figure 1 Electrorectogram showing the pacesetter and action potentials of a healthy volunteer 


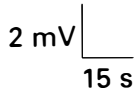

$15 \mathrm{~s}$

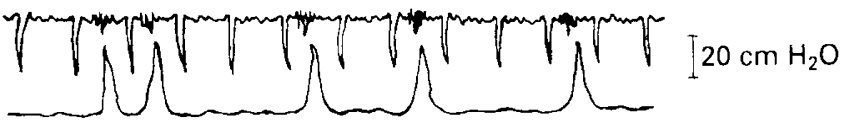

Figure 2 Electrorectogram of a healthy volunteer (upper tracing) with simultaneous rectal pressure recording (lower tracing). The rectal pressure recorded an increase only with the occurrence of action potentials

Meanwhile, the rectal neck pressure exhibited insignificant changes $(P>0.05)$; it ranged from 75 to $88 \mathrm{~cm}$ $\mathrm{H}_{2} \mathrm{O}$ (mean $82.2 \pm 6.4$ s.d. $\mathrm{cm}_{2} \mathrm{O}$ ). The number of AP, though inconsistent, coincided with the number of increased rectal pressure episodes (Figure 2). The higher the AP amplitude, the higher the rectal pressure readings. Table 2 depicts the rectal and rectal neck pressure recorded simultaneously with the rectal electric activity. The mean rectal pressure at rest was $12.8 \pm 2.1$ s.d. $\mathrm{cm} \mathrm{H}_{2} \mathrm{O}$ and during $\mathrm{AP}$ bursts $32.8 \pm 4.6$ s.d. $\mathrm{cm} \mathrm{H}_{2} \mathrm{O}(P<0.01)$.

The aforementioned results were the mean of a recording time varying from 480 to 720 min (mean $608.6 \pm 73.8$ s.d. $\mathrm{min}$ ), and were reproducible in the individual subject.

\section{Electrorectogram in spastic paralysis patients}

The introduction and fixation of the electrodes in the rectum were more difficult than was encountered in the normal volunteers or in the flaccid paralysis patients, due to lower limb spasticity and increased anal sphincter tone. However, the procedure was easily performed when the patient was placed in the left lateral position.

PP were recorded in all of the patients; they occurred with irregular frequency, amplitude and velocity of conduction. All types of rectal dysrhythmia occurred in the individual subjects (Figure 3). Bradyrectia, tachyrectia and rectoarrhythmia were all recorded in the same session of one patient. Moreover, the recording pattern of PP was not reproducible in the individual subject. In the meantime, AP did not show in any of the

Table 2 The rectal and rectal neck pressure recorded with the rectal electric activity in nine healthy volunteers. The rectal pressure increase occurred simultaneously with bursts of action potentials $(\mathrm{AP})^{\mathrm{a}}$

\begin{tabular}{|c|c|c|c|c|}
\hline & \multicolumn{4}{|c|}{ Pressure $\left(\mathrm{cm} \mathrm{H}_{2} \mathrm{O}\right)$} \\
\hline & \multicolumn{2}{|c|}{ Rectal } & \multicolumn{2}{|c|}{ Rectal neck } \\
\hline & Range & Mean & Range & Mean \\
\hline At rest & $9-14$ & $12.8 \pm 2.1$ & $75-88$ & $81.6 \pm 7.3$ \\
\hline During AP & $25-40$ & $32.8 \pm 4.6^{* *}$ & $73-86$ & $80.2 \pm 6.9^{*}$ \\
\hline
\end{tabular}

a Values are given as mean \pm standard deviation

$* P>0.05$

$* * P<0.01$

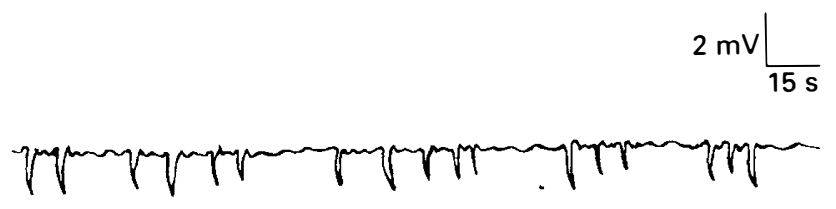

Figure 3 Electrorectogram of a spastic paralysis patient showing dysrhythmia with absent action potentials

subjects during the period of recording which ranged from 600 to $960 \mathrm{~min}$ (mean $840.6 \pm 96.3$ s.d. $\mathrm{min}$ ). The rectal and rectal neck pressure showed a significant increase $(P<0.01$ and $P<0.05$, respectively). The former recorded values between 36 and $56 \mathrm{~cm} \mathrm{H}_{2} \mathrm{O}$ (mean $47.7 \pm 8.4$ s.d. $\mathrm{cm} \mathrm{H}_{2} \mathrm{O}$ ) and the latter between 106 and $136 \mathrm{~cm} \mathrm{H}_{2} \mathrm{O}$ (mean $121.8 \pm 21.6$ s.d. $\mathrm{cm} \mathrm{H}_{2} \mathrm{O}$ ).

\section{Electrorectogram in flaccid paralysis patients}

The lax lower limbs and anal sphincters made electrode introduction and fixation into the rectum easy. A 'silent' electrorectogram was achieved in these patients (Figure 4). Neither PP nor AP were recorded in any patient during the period of study which varied from 600 to 960 min (mean $860.7 \pm 88.6$ s.d. $\min$ ). The 'silent' electrorectogram was reproducible on each single test day in all the subjects examined. The rectal pressure recorded insignificant values from the healthy volunteers $(P>0.05)$, while the rectal neck pressure showed significant decrease $(P<0.05)$. The latter recorded values between 32 and $48 \mathrm{~cm} \mathrm{H}_{2} \mathrm{O}$ (mean $41.7 \pm 8.8$ s.d. $\mathrm{cm} \mathrm{H}_{2} \mathrm{O}$ ).

\section{Discussion}

Rectal dysfunction is a frequent finding in those who have sustained a serious spinal cord injury. Depending on the level of the lesion, neurological examination demonstrates either supranuclear, nuclear or infranuclear lesions of the spinal cord. Immediately after a spinal cord injury, there is lack of reflex activity below the level of the lesion. During this stage of spinal shock, there is rectal areflexia; the tone of anal sphincters commonly returns some hours after the cord injury. The shock stage may last for days or months, after which the rectum remains areflexic as in those with the lower motor neuron lesions, or becomes hyperreflexic as in those with an upper motor neuron lesion.

In the present study, ERG of the 28 paraplegic patients recorded a picture different from that seen in normal volunteers. In patients with lower motor neuron lesions, the ERG showed neither PP nor AP in all the subjects despite the long recording time of the

$$
2 \mathrm{mV} \frac{}{15 \mathrm{~s}}
$$

Figure 4 'Silent' electrorectogram of a patient with flaccid paralysis: no pacesetter or action potentials 
electrical activity. The 'silent' ERG seems to be characteristic for lower motor neuron cord injuries. The absence of both PP and AP probably indicates absence of contractile activity of the rectum.

On the other hand, the ERG of those with an upper motor neuron injury showed PP but no AP. The PP exhibited an irregular rhythm with varying amplitude and velocity in the same individual, a condition of 'dysrhythmia'. Although an ERG was not reproducible in the individual subject, yet the dysrhythmic pattern was constant. No AP were recorded in any subject. AP were accompanied, in the controls, with increased rectal pressure indicating contractile rectal activity. Recording of PP without AP would point to the existence of rectal electrical but not contractile activity. The electrical activity was, however, irregular. This state of dysrhythmia in patients with upper motor neuron lesions indicates a non-harmonised rectal activity. The cause and significance of this dysrhythmia is unknown. It could be due to derangement of the intrinsic rectal conducting system, whether neurogenic or myogenic, resulting from the cord injury. Alternatively, it could result from a spastic anal sphincter accompanying this type of cord injury with a resulting detrusor sphincter dyssynergia which would disturb the harmony in the PP conduction along the rectal musculature. The dysrhythmia with absence of AP that initiate the contractile rectal activity, as well as the presence of spasticity of the external anal sphincter would explain the difficulty in rectal evacuation encountered in these patients. It may be argued that, in patients with an upper motor neuron injury, there was a high rectal pressure although the AP were absent. It appears that the high rectal pressure is due to a high intrinsic tone, which may have a role in abolishing the AP.

The electrorectography records the electric activity of the rectal detrusor. Disorders of this activity would disturb rectal function. The functional detrusor activity seems to be more adequately identified by electrorectography than by other investigative methods such as manometric or radiological studies. According to the electrorectographic pattern (normal or dysrhythmic) treatment could be planned and followed up. The method is non-invasive and non-radiological and could be included as an investigative tool in the assessment of rectal function.

\section{Acknowledgement}

We are grateful to Mrs Margot Yehia who revised the manuscript.

\section{References}

1 Adams RD, Sidman RL. Introduction to Neuropathology. McGraw Hill Book Co: New York, 1968, pp 28-42.

2 Adams RD, Victor M. Principles of Neurology. McGraw Hill Book Co: New York, 1977, pp 46-66.

3 Trevor Hughes J. Pathology of the Spinal Cord. WB Saunders Co: Philadelphia, 1978, pp 35-65.

4 Percy JP, Neill ME, Swash M, Parks AG. Electrophysiological study of motor nerve supply of the pelvic floor. Lancet 1982; i: $16-17$.

5 Snooks SJ, Setchell M, Swash M, Henry MM. Injury to the innervation of the pelvic floor musculature in childbirth. Lancet 1985; ii: $546-550$.

6 Gowers WR. The autonomic action of the sphincter. Proc $R$ Soc (London) 1877; 26: 77-84.

7 Denny-Brown D, Robertson EG. An investigation of the nervous control of defecation. Brain 1935; 58: 256-310.

8 Bouvier M, Gonella J. Electrical activity from smooth muscle of the anal sphincter area of the cat. J Physiol 1981; 310: 445-456.

9 Taylor BM, Beart BW, Phillips SF. Longitudinal and radial variations of pressure in the human anal sphincter. Gastroenterology 1984; 86: 693-697.

10 Pennincks F, Mebis JH. The recto-anal reflex in cats analysed in vitro. Scand J Gastroenterol 1982; 17(Suppl 71): 147-149.

11 Pedersen E, Harving H, Klemar B, Torring J. Human anal reflexes. J Neurol Neurosurg Psychiatry 1978; 9: 813-818.

12 Shafik A. Constipation. Some provocative thoughts. J Clin Gastroenterol 1991; 13: 259-267.

13 Shafik A. Study of the electrical and mechanical activity of the rectum. Experimental study. Eur Surg Res 1994; 26: 87-93.

14 Shafik A. Study of the electromechanical activity of the rectum. II. Human study. Coloproctology 1993; 15: 215-218.

15 Shafik A. Electrorectography in chronic proctitis. World J Surg 1993; 17: 675-679.

16 Shafik A. Electrorectogram in Hirschsprung's disease: a new diagnostic tool. Proc 28th Congress of European Society of Surgical Research, 1993, Turku, Finland.

17 Shafik A. Rectosigmoid pacemaker. Role in defecation mechanism and constipation. Dis Colon Rectum 1992; 35: 29-30 (abstract).

18 Shafik A. Artificial pacemaker for rectal evacuation. Coloproctology 1992; 14: 96-98.

19 Shafik A. A new concept of the anatomy of the anal sphincter mechanism and the physiology of defecation. XIV Anal canal: a fallacious anatomical and embryological entity. Am J Proctol Gastroenterol Colorectal Surg 1982; 33: 14-23.

20 Shafik A. A concept of the anatomy of the anal sphincter mechanism and the physiology of defecation. Dis Colon Rectum 1987; 30: 970-982. 